\title{
Antibacterial Effect of Endophytic Actinomycetes from Marine Algae against Multi Drug Resistant Gram Negative Bacteria
}

\author{
Govindan Rajivgandhi', Govindan Ramachandran", Muthuchamy Maruthupandy², \\ Subramaniyan Saravanakumar ${ }^{1}$, Natesan Manoharan ${ }^{1 *}$ and Rajendran Viji ${ }^{3}$ \\ ${ }^{1}$ Medical Microbiology \& Pharmocology Unit, Department of Marine Science, Bharathidasan University, Tiruchirappalli, Tamil Nadu, India \\ ${ }^{2}$ Department of Packaging, Yonsei University, Gangwondo 220-710, Republic of Korea
}

${ }^{3}$ Environmental Microbiology and Toxicology Laboratory, Department of Environment Management, Bharathidasan University, Tiruchirappalli, Tamil Nadu, India

*Corresponding author: Manoharan N, Medical Microbiology \& Pharmacology Unit, Department of Marine Science, Bharathidasan University, Trichirappalli 24, India

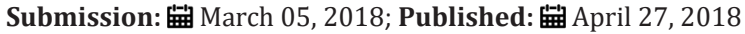

\begin{abstract}
The discovery of new broad spectrum antibiotics is urgent need to combat frequently emerging multi drug resistant pathogens (MDR) Actinomycetes, the most important group of microorganisms isolated from marine sources of the world may be the conclusive solution to this problem. Thus the aim of present study was to isolate and identify many secondary metabolite producing actinomycetes from algae sources. The 20 strains of endophyticactinomycetes were screened from marine green algae Cauler pataxifolia and the surface sterilization was proved, the isolates were internal tissue of the algae. Among the 20, 5 strains have better antibacterial activity against multi drug resistant uropathogens by agar well diffusion method. Interestingly, DMS 3 showed excellent inhibition activity against all uropathogens by various solvent systems. Among the various solvent systems, ethyl acetate was exhibited excellent inhibitory activity and showed $24,27,20,19,16 \mathrm{~mm}$ zone against E. coli, P. aeroginosa, K. pneumonia, Enterobacter sp respectively. The MIC and MBC also confirmed that the actinomycete strain DMS 3 as excellent antibiotic producer against MDR. It inhibits MDRs of uropathogens at very lowest concentration $(100 \mu \mathrm{g} / \mathrm{ml})$.
\end{abstract}

Keywords: Urinary tract infections; Gram negative bacteria; Multi drug resistant bacteria; Minimum inhibition concentration; Endophytic actinomycetes

\section{Introduction}

Urinary tract infections (UTIs) are the standout among the most human infections but they are frequently presented in the world and they are second most dangerous disease after the respiratory infection [1]. It continuous as a critical threat with significant rate of mortality and morbidity along prodigious economic loss. The diagnosis and eradication is still unclear since linked to other major diseases in community and hospital settings and sometimes asymptomatic indication [2]. The burden of antimicrobial resistance in UTI is the major problem thereby constant discussion and a relentless effort has been initiated across the world. The bacterial resilience to antibiotic is significant to medical industry and global threat in the treatment of urinary tract infections (UTIs). It greatly alarmed that the incidence of MDR development and infection are increasing in UTIs [3].

Treatment of such MDR is also another important problem since the pathogens are almost resistant to current antibiotics and they easily develop resistance to the new drugs also [4]. In particular, Gram negative bacteria (GNB) play a vital role in UTIs due to synthesizing some enzymes, efflux pump, target site modification, etc [5]. In recent years MDRs of GNB in UTIs are increased significantly and show resistance to at least one drug most commonly preferred for prevent and few are resistant to all antibiotics [6]. It most often inhabit in the UTIs of human and veterinary, and difficult to treat [7]. It causes recurrent infections (40-75\%) in UTIs due to improper usage, un prescribed format of antibiotics, over dosage and long-term treatment in human, agro farms and veterinary [8]. In modern evolutionally, one from a recent generation of these antibiotic classes should not be working properly against MDR uropathogens, further complications, cystitis, urethritis, pyelonephritis and a severe bacteremia there after returning in the next few days eventually and face of an unknown antibiotic resistance in the causative bacterium exhibited more fatality [9]. Most important UTI bacteria including Escherichia coli, Proteusmirabilis, Pseudomonas aeruginosa, Kilebsiella pneumonia, Enterobacter sp and Serratiamarcescens [10]. These pathogens are completely resistance to all classes of drugs and can inhibit due to use with experimental and potential toxic drugs studies only. The loss of drug potency and its effective against resistance pathogens was depends on the drugs and pathogens with critical disease [11]. Therefore, there is urgent need to find new types of drugs to inhibit the resilient bacteria and decrease the healthcare infections. 
The $70 \%$ of earth was made by ocean [12]. It had fabulous characteristics as synthesis of useful materials for human, animal and healthcare settings including secondary metabolites which act against infectious diseases and inflammation. In this environment, microbes have tremendous rich sources of bioactive metabolites [13]. Among the microorganisms, action bacteria is a Gram positive bacteria, spore forming bacteria having filamentous and the colony morphology is coarsely wrinkled or folded, it produce significant sources of new molecules with pharmacological properties which are lead compound for the various infections [14]. In the alternative study of novel antibiotic finding, endophytic actinomycetes which emerging from internal tissues of the plant algae and synthesize new types of drugs from medical and infections [15] It varied from other actinomycetes by utilize the nutrients, sugar moieties, carbohydrate polymers, amino acids and peptides from plants and algae with different concentrations. Some differences could be expected among the organisms for new therapeutic outlook to prevent and or the major endophytic actinomycetes have nuclear therapeutic value and yet to afford attention to discover pyronone, taxol, camtothecin, and phenylproponoid like compounds. Previously, Alnumycin, munumbicins A to D [16], coronamycins and anthraquinones, lupinacidins A and B [17] are some of the natural compounds that reported earlier form marine endophyticactinomycetes. It has an excellent inhibition ability and interact with structure of cells including cell wall, ROS and some metabolic pathways and lead to permeability, target achievement etc.. Further, these compounds showed extensive range of biomedical applications including cytotoxic, antimicrobial, antimalarial, anticancer, immunosuppressant [18,19], antiinflammatory, anthelmintic, herbicide, enzyme etc., $[20,21]$. However, limited research has available on the identification of new compound from marine endophytic actinomycetes against MDRs uropathogens. Hence, present study was concentrated on isolation, identification, partial purification of antibacteria compound from marine endophytic actinomycetes and its potential effect against MDRs uropathogens.

\section{Materials and Methods}

\section{Collection of samples}

The young leaf of green algae Cauler pataxifolia was collected from Gulf of Mannar region (Latitude 9 ${ }^{\circ} 15^{\prime} 41.88$ ” N, Longitude $79^{\circ} 04^{\prime} 05.81^{\prime \prime E}$ ), Mandapam coastal area, Rameswaram, Southeast coast of Tamil Nadu, India. The collected algae was sealed with sterile plastic cover and kept in ice box. The sample was completely washed with tap water and followed by distilled water for removal of the free floating organisms. Surface sterilization of $70 \%$ ethanol was used for removal of epiphytes.

\section{Isolation of endophytic actinomycetes}

The endophytes was isolated from surface sterilization method was performed by following procedure $[22,23]$. The algal samples were thoroughly washed with tap water, and small fragments of leaves, twigs, and buds of approximately $10 \mathrm{~mm}$ (length) were cut aseptically by using sterile scale pale. Then, the small fragments were surface sterilized by $70 \%$ ethanol for $1 \mathrm{~min}$ and followed by $1.3 \mathrm{M}$ sodium hypochlorite ( $3-5 \%$ available chlorine) for $3 \mathrm{~min}$, and $70 \%$ ethanol for 30s. Finally, these surface-sterilized tissue pieces were rinsed thoroughly in sterile, double-distilled water for $2 \mathrm{~min}$, to remove excess surface sterilants. The excess moisture content was wiped by sterile cotton. The surface-sterilized tissue fragments, thus obtained, were evenly placed (four fragments in each plate) in starch casein agar medium (SCA) incorporated with streptomycin $(100 \mathrm{mg} / \mathrm{l})$ to remove any bacterial growth. All the plates were incubated at $28^{\circ} \mathrm{C}$ for $6-7$ days. To ensure proper surface sterilization and isolation of endophytes, unsterilized tissue fragments (only washed thoroughly in water) were prepared simultaneously, placed in SCA, and incubated under the same conditions in parallel, to isolate the surface-contaminating organisms (differentiated morphologically by both macroscopic and microscopic evaluation) [23]. The cultures were monitored daily to observe the growth of endophytic actinomycetes. The endophytic organisms, which grew out from the sample segments over 4-6 weeks were isolated and subcultured onto aactinomycetes isolation agar (AIA) and got into pure culture. To perform proper surface sterilization, surfacesterilized tissue fragments were imprinted simultaneously in SCA and AIA and incubated under the same conditions in parallel [24].

\section{Primary screening of actinomycetes}

The antagonistic activity of isolated endophytic actinomycetes was tested against chosen MDRs uropathogens by conventional cross streak method [25]. The isolated strains were streaked across the diameter on mullerhinton agar (MHA) plates. All the plates were incubated at $28^{\circ} \mathrm{C}$ for 6-7 days. After observing ribbon, white colour growth of the strain, the $24 \mathrm{~h}$ uropathogens were streaked perpendicular to the angle of central strip of the actinomycetes culture. All the plates were incubated at $37{ }^{\circ} \mathrm{C}$ for $24 \mathrm{hrs}$. After incubation, the antagonistic positive strains were observed due to the inhibition effect and these strains were chosen for further study. The active potential of DMS 3 culture filtrate was added with equal volume of five various solvents (acetone, petroleum ether, ethyl acetate, chloroform, and methanol) and shaken for $1 \mathrm{hr}$. The antibacterial activity of extracted filtrates was tested against selected uropathogens by agar well diffusion method [26].

\section{Extraction of bioactive compounds from DMS 3}

The antibacterial potential of actinomycete DMS 3 was extracted with active solvent of ethyl acetate by liquid- liquid extraction method [27]. The DMS 3 strain was inoculated in actinomycete isolating broth (AIB) and the broth was incubated at $28^{\circ} \mathrm{C}$ for 15 20 days. After fermentation the broth was centrifuged at 5000rpm for 15 minutes and the supernatant was filtered by Whattman No.1 filter paper. Equal volume of ethyl acetate was added with filtrate of supernatant in the ratio of $1: 1(\mathrm{w} / \mathrm{v})$ and shaken vigorously $1 \mathrm{hr}$ for complete extraction. The organic phase was separated from aqueous phase using separating funnel and evaporated with water bath at 40 to $50{ }^{\circ} \mathrm{C}$. After evaporation, the dried crude compounds were collected and determined the antimicrobial activity against MDRs of uropathogens by agar well diffusion method. 


\section{Secondary screening}

The antibacterial ability of DMS 3 was tested against MDRs uropathogens at regular intervals $(24 \mathrm{~h}, 48 \mathrm{~h}, 96 \mathrm{~h})$ by well-diffusion method [28]. Briefly, the $24 \mathrm{hrs}$ cultures of uropathogens were spread on MHA plates and wells were cut using gel borer. The four concentration $(25,50,75,100 \mu \mathrm{l})$ of the extract was added separately into the each well. The ethyl acetate extract act as a control. All the plates were incubated at $37^{\circ} \mathrm{C}$ for $24 \mathrm{hrs}$. After $24 \mathrm{hrs}$ all the plates were observed for the zone of inhibition around the wells.

\section{Determination of MIC and MBC}

The MIC of DMS 3 was performed against selected MDR uropathogens by micro broth dilution method using 96-well plate and the result was calculated by spectrophotometer [29]. Briefly, all the wells were filled with fresh TSB broth incorporated with $24 \mathrm{hrs}$ bacterial cultures. Different concentration $(10,20,30,40,50,60$, $70,80,90,100 \mu \mathrm{g} / \mathrm{ml}$ ) of DMS 3 extract was added into the plate. The two fold serial dilution was done in to 11 following wells. The final volume of each well contained $100 \mu$ l. The sterile broth with test pathogen was acted as control. Each plate was mixed well and then incubated at $37^{\circ} \mathrm{C}$ for $24 \mathrm{~h}$. After $24 \mathrm{hrs}$ no visible growth was observed in the plate. If the lowest concentrations of the extract inhibited the growth was indicated as MIC. The plates were read with UV spectrophotometer at $570 \mathrm{~nm}$ and percentage of inhibition was calculated by using the following formula.

Percentage of inhibition:

(Control OD570nm - Test OD570nm) $\mathrm{X} 100$

Control OD570nm

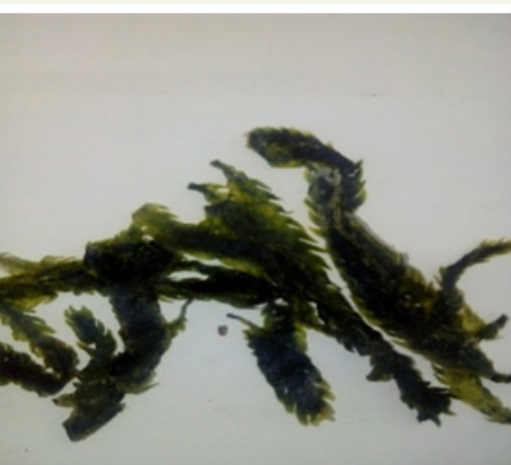

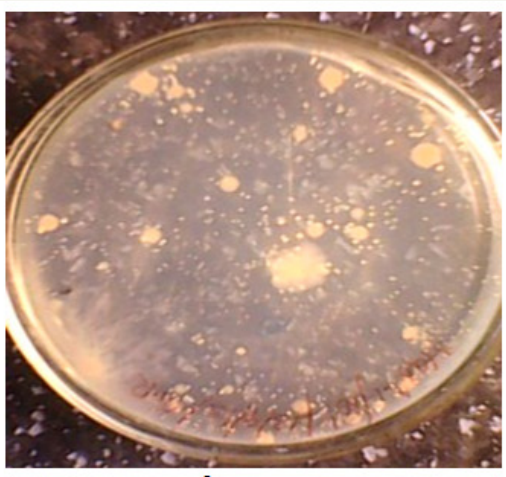

b

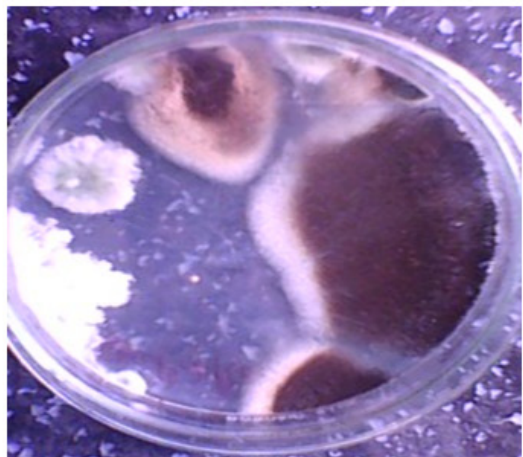

Figure 1: Isolation of endophytic actinomycetes from marine alage.

(a) Caulerpa taxifolia

(b) Endophytic actinomycetes from surface sterilized sample.

(c) Contamination of other organisms grown in non surface sterilized sample plates.

\section{Primary screening and antagonistic activity}

Based on the antagonistic activity, 20 strains of actinomycetes were determined from antimicrobial activity against MDRs uropathogens. Among the 20 strains, 5 strains have better antagonistic activity against selected uropathogens were observed
Likewise, $10 \mu \mathrm{L}$ of MIC concentration was aliquot from treated bacteria broth and streaked on MHA plates. All the plates were incubated at $37^{\circ} \mathrm{C}$ for $24 \mathrm{~h}$. After incubation, the highest inhibition of the growth was observed from the minimum concentration of the MIC was indicated as MBC.

\section{Result}

\section{Isolation and identification of endophytic actinomycetes}

The young fine leaves of green algae (Figure 1) were collected from Gulf of Mannar region), Mandapam coastal area, Rameswaram, Southeast coast of Tamil Nadu, India. Surface sterilization of leaves were validated and showed no any microbial colonies present in the ISP 2 plates. The result was indicated, the sterilization was excellent. After validation, the 50 numbers of pure, fine, ribbons like powdery white color colonies of endophytic actinomycete were isolated from the algal sample and streaked on SCA and AIA medium. The isolated strains were recorded in (Figure 1a \& 1b). In parallel, the isolates were originating from internal tissue of the plates were identified by more microbial contamination in the unsterilized tissue of the algal plates were observed (Figure 1c). Approximately 20 isolated strains were showed antimicrobial activity against selected uropathogens. These active strains were chosen for further study for the production of bioactive compounds. The result was proved that the isolated actinomycetes were emerged from internal tissues of the algae. Recently, Rajivgandhi et al. [30] reported that marine endophytic actinomycetes have excellent inhibitory activity against MDRs pathogen. Our result was accordance with earliest finding of Passari et al. [31] and reported that the hypochlorite was better choice for surface sterilization to algae, plant derived endophytic actinomycetes. 
observed (Figure 3). In the antibacterial activity of the ethyl acetate crude extract of the isolated actinomycete were showed better inhibition against selected uropathogens than other solvent were clearly observed (Figure 3). Hence, ethyl acetate extract of the DMS
3 was chosen for further study. The actinomycete was frequently identified from various marine sources and it produced new classes of antibiotics against various clinical disorders [32].
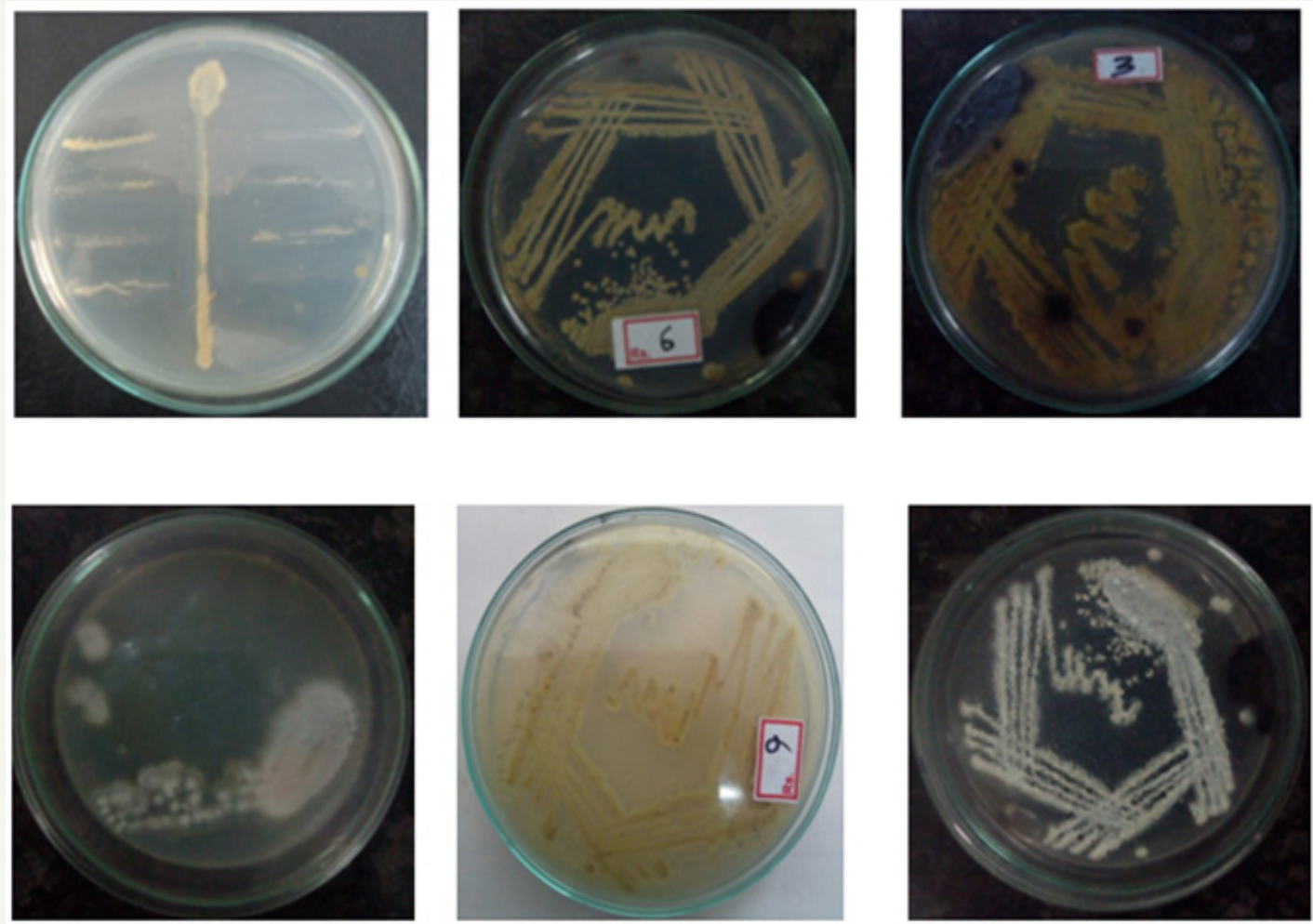

Figure 2: a). Antogonistic activity of isolated strains and screening of active endophytic actinomycetes ( b, c, d, e, f)

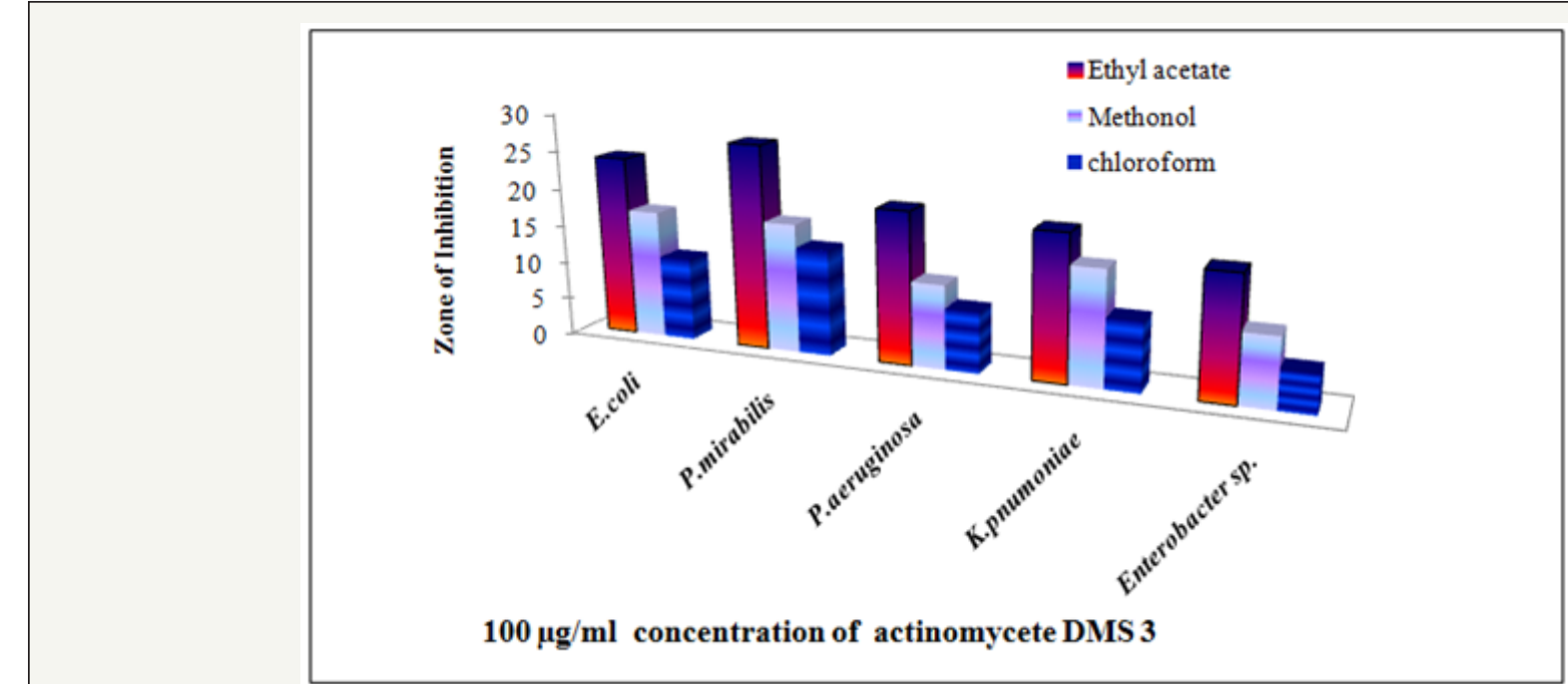

Figure 3: Ethyl acetate extract of DMS 3 showed excellent inhibitory activity against all uropathogens.

Table 1: Identification of endophytic actinomycetes.

\begin{tabular}{|c|c|c|}
\hline S. No & Strains & Antagonistic Activity \\
\hline 1 & DMS 1 & Excellent Activity \\
\hline 2 & DMS 2 & Excellent Activity Activity \\
\hline 3 & DMS 3 & Good Activity \\
\hline 4 & DMS 4 Good Activity \\
\hline 5 & DMS 5 & G
\end{tabular}


Extraction and antimicrobial activity of secondary metabolites from DMS 3

The potential strain of DMS 3 was showed excellent antibacterial activity was chosen and the active compound was extracted by ethyl acetate extraction. After, extraction, the aqueous phase and organic phase was collected separately (Figure 4a). Consecutively, the organic phase was maintained in the incubater at $40 \mathrm{oC}$ for complete evaporation. After evaporation, the crude compound were collected and mixed with ethyl acetate for further use. In the secondary screening of antibacterial activity, the ethyl acetate extract of the DMS 3 has produced excellent zone of inhibition against all the pathogens including 24, 27, 20, 19, 16mm were observed against E. coli, P aeroginosa, K pneumonia, Enterobacter sp (Figure 4), respectively (Figure 4a \& 4b). No zone of inhibition was observed in the control well. Hence, the result was confirmed that the ethyl acetate extract of the DMS 3has more bactericidal. Our result was most accordance with earliest study of Gulve et al. [33] and reported that ethyl acetate was better solvent for production of active metabolites from actinomycetes strains.
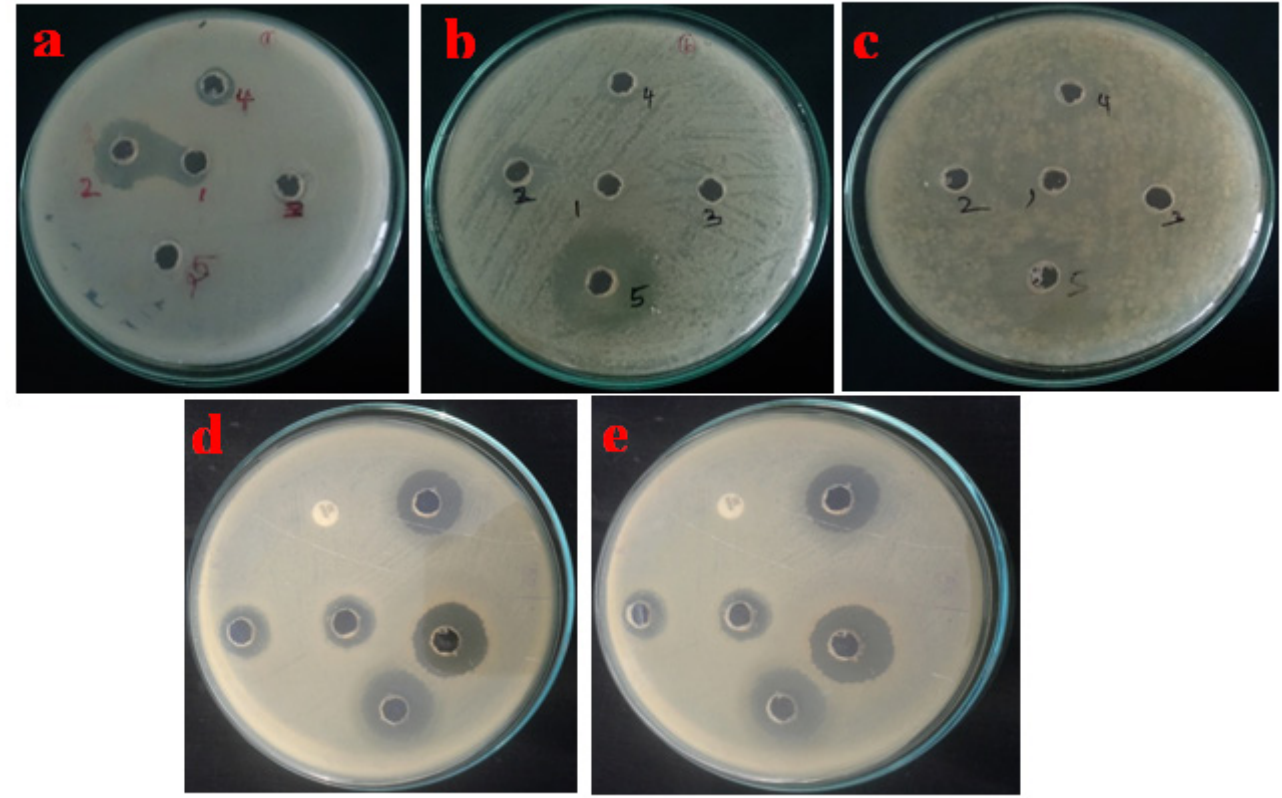

Figure 4: Extraction and antibacterial activity of DMS 3 (a). Ethyl acetate extraction of DMS 3 (b) ethyl acetate extraction of DMS 3 extract against various uropathogens (a). E. coli, (b). P. mirabilis. (c). P.aeruginosa, (d). K.pnumoniae (e). Enterobacter sp.

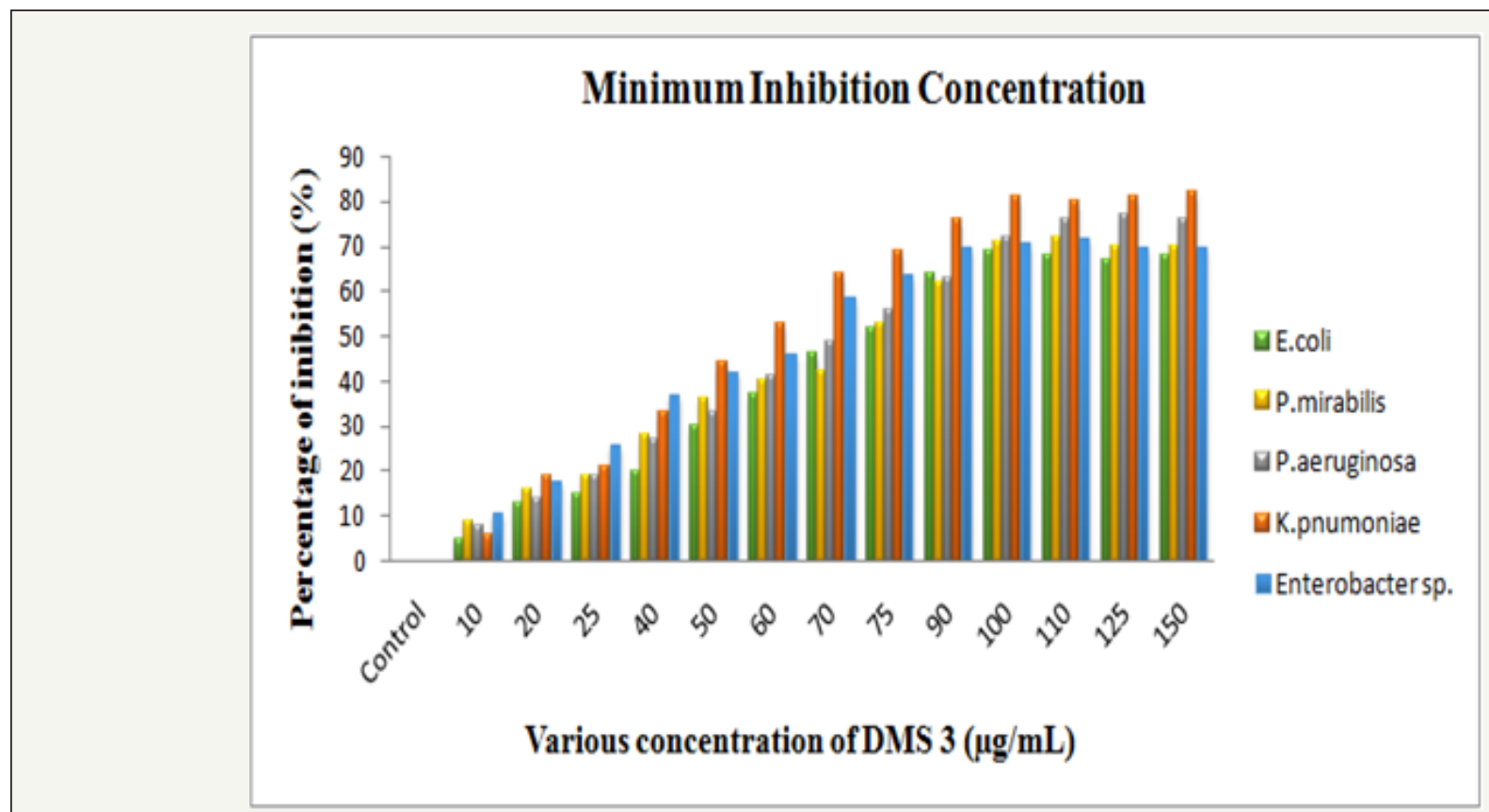

Figure 5: Minimum inhibition concentration of DMS 3 against uropathogens. 
The supportive evidence of Kumari Pushpa Rani et al. [34] also evidenced, marine derived actinomycetes compound has highest inhibition against Gram negative bacteria and 23, 25, 19 and 24mm zone of inhibition against S. aureus, E. coli, P. aeruginosaand, B. subtilis were observed.

\section{MIC and MBC}

The bacteriostatic and bactericidal properties of DMS 3 was performed against Gram negative buropathogens E. coli, P. mirabilis, P. aeroginosa, K. pneumonia, Enterobacter sp by microbroth dilution method. After treatment of $24 \mathrm{hrs}$, the cell multiplication was decreased and the ability of bacterial characters also loosed. The highest growth inhibition was observed at $69,71,72,80$, $72 \%$ of inhibition was observed at $100 \mu \mathrm{g} / \mathrm{mL}$ concentration. The bacterial growth was decreased by increasing concentration of the ethyl acetate extract. In the $100 \mu \mathrm{g} / \mathrm{mL}$ concentration, the bacteria K. pnumoniae was completely arrested and other pathogens also nearby same also observed. Hence, $100 \mu \mathrm{g} / \mathrm{ml}$ was selected as MIC and this concentration was used for further study (Figure 5).

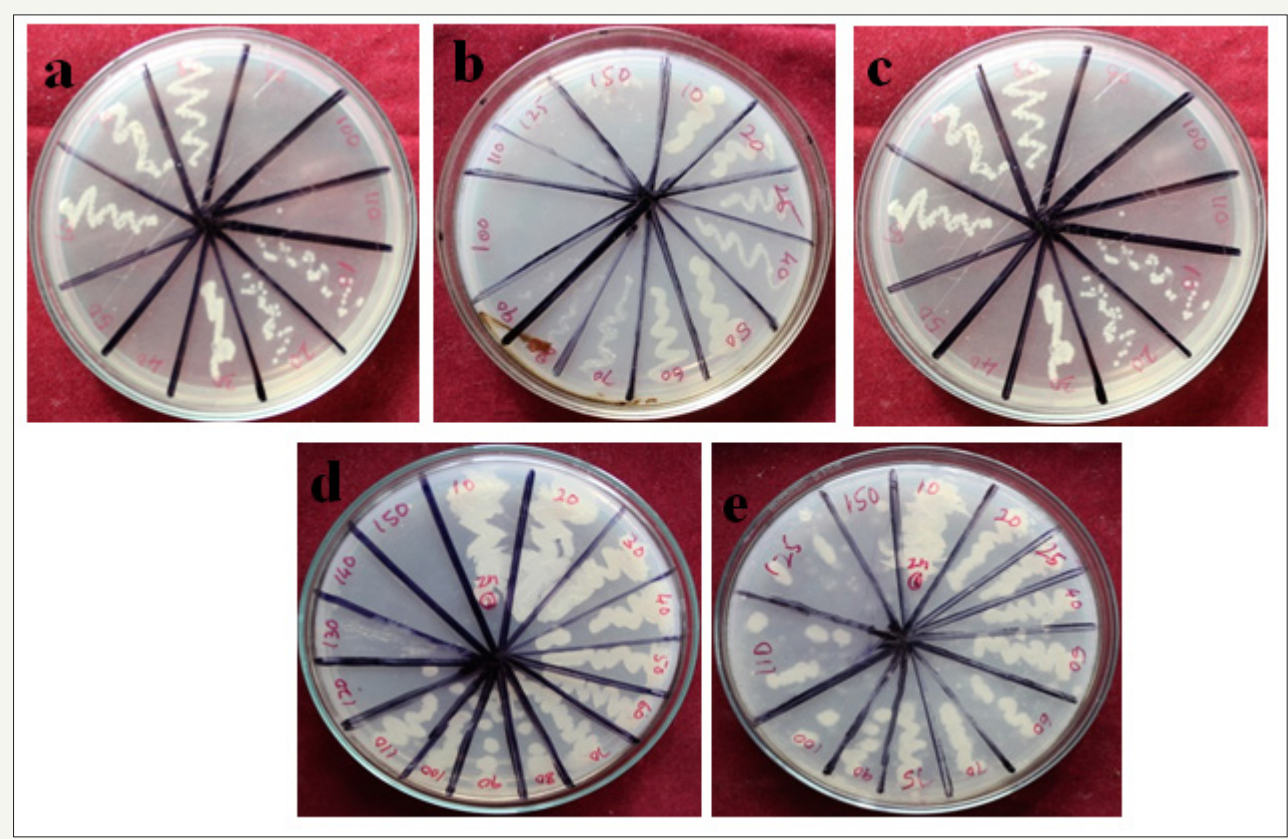

Figure 6: Minimum bacterial concentration of DMS 3 against uropathogens.

(a). E. coli (b). P. mirabilis. (c). P.aeruginosa, (d). K.pnumoniae (e). Enterobacter sp.

The misinterpretation of MIC was checked due to turbidity of insoluble compounds into the broth of micro dilution plate, MBC was detected by culturing the MIC dilutions on the fresh MHA plates with different concentration $(10-100 \mu \mathrm{g} / \mathrm{mL})$ of DMS. In the MBC plates, no any visible growth were observed at same MIC concentration was observed (Figure 6). The rate of inhibition effect was slightly differed from bacteria to bacteria. However, the result suggested that the increasing concentration of DMS 3 was better inhibitor for MDRs. Both MIC and MBC results confirmed, DMS can be used to control the multi drug developing bacteria in UTIs. Previous studies have reported those chemical constituents of actinomycetes extract have excellent antibacterial agents $[35,36]$. They have identified the active compounds from endophytic actinomycetes were may be alkaloids (Figure 6).

\section{Conclusion}

In the present study, the new collection of actinomycetes was identified from marine sources in Gulf of mannar region and it shows excellent secondary metabolites against drug resistance pathogens. In result, isolated DMS 3 extract has an excellent antibacterial activity against MDRs uropathogens at very low concentration. MIC also proved that the, DMS 3 has potential chemical constituent for inhibiting the uropathogens. Therefore isolation and identification of DMS 3 has been useful in discovery of new classes of antibiotics. The secondary metabolites may be evolved in nature as some kind of response to the interplay of microbial genetics and natural product chemistry. Thus, our study brings forward a good promise for future drug development and agricultural programs [37].

\section{Reference}

1. Aue S, Wojna A, Hell M (2010) Oral treatment options for ambulatory patients with urinary tract infections caused by extended-spectrum $\beta$-lactamase-producing Escherichia coli. Antimicrob Agents chem 54(9): 4006-4008.

2. Mohammed MA, Alnour TM, Shakurfo OM, Aburass MM (2016) Prevalence and antimicrobial resistance pattern of bacterial strains isolated from patients with urinary tract infection in Messalata Central Hospital, Libya. Asian Pac J Trop Med 9(8): 771-776.

3. Shahi SK, Kumar A (2016) Isolation and Genetic Analysis of Multi drug Resistant Bacteria from Diabetic Foot Ulcers. Front Microbiol 6: 1464.

4. Rajivgandhi G, Marudupandy M, Ramachandran G, Priyanga M, Manoharan N (2018) Detection of ESBL genes from ciprofloxacin resistant Gram negative bacteria isolated from urinary tract infections (UTIs). Frontiers in Laboratory Medicine. 
5. Kelly O, Kavanagh F, Manecksha S, Thornhill RJ, Fennell JP (2016) Characteristics of gram negative urinary tract infections caused by extended spectrum beta lactamases: pivmecillinam as a treatment option within South Dublin, Ireland. BMC Infect Dis 16(1): 620.

6. Paterson DL (2006) Resistance in gram- negative bacteria: Enterobacteriaceae. Am J med 119 (6 Suppl 1): S20- S62.

7. Rajivgandhi G, Maruthupandy M, Manoharan N (2018) Detection of TEM and CTX-M genes from ciprofloxacin resistant Proteus mirabilis and Escherichia coli isolated on urinary tract infections (UTIs), Microbial pathogenesis accepted.

8. Moges F, Endris M, Belyhum Y, Worku W (2014) Isolation and characterization of multiple drug resistance bacterial pathogens from waste water in hospital and non-hospital environments, North West Ethiopia. BMC Res Notes 7: 215

9. Chourasia E, Singh KP, Kher SK (2005) Extended Spectrum Beta ( $\boldsymbol{\beta})$ Lactamases in Clinical isolates of Gram-Negative Bacilli in Ajman, United Arab Emirates. GMJ 4(1): 14-21.

10. Rajivgandhi G, Vijayarani J, Kannan M, Murugan A, Vijayan R, Manoharan $\mathrm{N}$ (2014) Isolation and identification of biofilm forming uropathogens from urinary tract infection and its antimicrobial susceptibility pattern. International Journals of Advanced Life Sciences. 7:352-363.

11. Kateregga JN, Kantume R, Atuhaire C, Lubowa MN, Ndukui JG (2015) Phenotypic expression and prevalence of ESBL producing Enterobacteriaceae in samples collected from patients in various wards of Mulago Hospital, Uganda. BMC Pharmacol Toxicol 16: 14

12. Yu J, Zhang L, Liu Q, Qi X, Ji Y, Kim BS (2015) Isolation and characterization of action bacteria from Yalujiang coastal wetland, North China. Asian Pac J Trop Biomed 5(7): 555-560.

13. Naine J, Srinivasan MV, Devi SV (2011) Novel anticancer compounds from marine actinomycetes: a review. J Pharm Res 4: 1285-1287.

14. Engelhardt K, Degnes KF, Kemmler M, Bredholt H, Fjaervik E, et al (2010) Production of a new thiopeptide antibiotic TP-1161, by a marine Nocardiopsis species. Appl Environ Microbiol 76(15): 4969-4976.

15. Rajivgandhi G, Vijayan R, Kannan M, Santhanakrishnan M, Manoharan N (2016) Molecular characterization and antibacterial effect of endophyticactinomycetes Nocardiopsis sp. GRG1 (KT235640) from brown algae against MDR strains of uropathogens. Bioactive Materials 1(2): 140-150.

16. Antunes TC, Borba MP, Spadari CC, Antunes AL, Frazzon APG, et al. (2014) Screening of actinomycetes with activity against clinical isolates of gram positive cocci with multi resistant profile. J Adv Sci Res 5(1): 13-17.

17. Castillo UF, Strobel GA, Ford EJ, Hess WM, Porter H, et al. (2002) Munumbicins, wide-spectrum antibiotics produced by Streptomyces NRRL 30562, endophytic on Kennedia nigrisca. Microbiology 148: 26752685 .

18. Igarashi Y, Trujillo ME, Martínez Molina E, Yanase S, Miyanaga S, et al (2007) Antitumor anthraquinones from an endophytic actinomycete Micromonospora lupini sp. Bioorg Med Chem Lett 17(13): 3702-3705.

19. Kurtboke DI, French JR, Hayes RA, Quinn RJ (2015) Eco-taxonomic insights into actinomycete symbionts of termites for discovery of novel bioactive compounds. Adv Biochem Eng Biotechnol 147: 111-135.

20. Mann J (2001) Natural products as immunosuppressive agents. Nat Prod Rep 18(4): 417-430.

21. Blunt JW, Copp BR, Munro MHG, Keyzers RA, Prinsep MR (2011) Marine natural products. Nat Prod Rep 33(3): 382-431.

22. Kusari S, Pandey SP, Spiteller M (2013) Untapped mutualistic paradigms link-ing host plant and endophytic fungal production of similar bioactive secondary metabolites. Phytochemistry 91: 81-87.

23. Rajivgandhi G, Vijayan R, Maruthupandy M, Vaseeharan B, Manoharan N (2018) Antibiofilm effect of Nocardiopsis sp. GRG 1 (KT235640) compound against biofilm forming Gram negative bacteria on UTIs. Microb Pathogen 118: 190-198.

24. Fouda AH, Hassan SD, Eid AM, Ewais ED (2015) Biotechnological applications of fungal endophytes associated with medicinal plant Asclepiassinaica (Bioss.). Ann of Agricul Sci 60(1): 95-104

25. Wang L, Qiu P, Long XF, Zhang S, Zeng ZG et al. (2016) Comparative analysis of chemical constituents, antimicrobial and antioxidan activities of ethylacetate extracts of Polygonum cuspidatum and its endophyticactinomycete, Streptomyces sp. A0916. Chin J Nat Med 14(2): 117-123.

26. Jaganmohan YSYV, Sirisha B, Haritha R, Ramana T (2013) Selective screening, isolation and characterization of antimicrobial agents from marine actinomycetes. Int J Pharm and Pharm Sci 5(4): 443-449.

27. Liu CM, Westley JW, Herman TE, Prosser BL, Palleroni N, et al. (1986) Novel polyether antibiotics. X- 14873 A, G and H produced by streptomyces. Taxonomy of the producing culture, fermentation, biological and ionospheres properties of antibiotics. J Antibiot 39(12): 1712-1718.

28. Alade PI, Irobi ON (1993) Antimicrobial activity of crude leaf extract of Acalyphawilesiana. J Ethnopharmacol 39(3): 171-174.

29. Thulasi G, Amsaveni V (2012) Antibacterial activity of cassia auriculata against ESBL producing E. coli from UTI Patients. Int J Microbio Res 3(1): 24-29.

30. Lechevalier HA (1989) A Practical Guide to Generic Identification of actinomycetes. Bergey's Manual of Systematic Bacteriology, Williams \& Wilkins Company, Baltimore 4: 2344-2347.

31. Passari AK, Chandra P, Zothanpuia, Mishra VK, Leo VV, et al. (2016) Detection of biosynthetic gene and phytohormone production by endophytic actinobacteria associated with Solanum lycopersicum and their plant-growth-promoting effect. Res Microbiol 167(8): 692-705.

32. Rajan BM, Kannabiran K (2014) Extraction and Identification of Antibacterial Secondary Metabolites from Marine Streptomyces sp. VITBRK2. Int J Mol Cell Med 3(3): 130-137

A. Khattab I, Babiker EH, Saeed HA (2016) Streptomyces: isolation, optimization of culture conditions and extraction of secondary metabolites. Inter Current Pharmac Journal 5(3): 27-32.

33. Gulve RM, Deshmukh AM (2012) Antimicrobial activity of the marine actinomycetes. Int Multidisc Rese Journal 2(3): 16-22

34. KumariPushpa Rani TP, Doss A (2016) Purification and Antibacterial Activity of Marine Actinomycetes against Human and Fish Pathogens. J Marine Sci Res Dev 6: 1-4

35. Alzeus Q, Tantengco G, Jacinto SD (2015) Cytotoxic activity of crude extracts and fractions from Premnaodorata (Blanco), Artocarpus camansi (Blanco) and Gliricidiasepium (Jacq.) against selected human cancer cell lines. Asian Pac J Trop Biomed 5(12): 1037-1041.

36. El Sayed MH (2012) Di-(2-ethylhexyl) Phthalate, a Major Bioactive Metabolite with Antimicrobial and Cytotoxic Activity Isolated from the Culture Filtrate of Newly Isolated Soil Streptomyces (Streptomyces mirabilis Strain NSQu-25). World Appl Sciences Journal 20(9): 12021212.

37. Rajivgandhi G, Maruthupandy M, Muneeswaran T, Anand M, Manoharan $\mathrm{N}$ (2018) Antibiofilm activity of zinc oxide nanosheets (ZnO NSs) using Nocardiopsis sp. GRG1 (KT235640) against MDR strains of gram negative Proteus mirabilis and Escherichia coli. Process Biochemistry 67: 8-18. 
Creative Commons Attribution 4.0 International License

For possible submissions Click Here

Submit Article
EIMBO

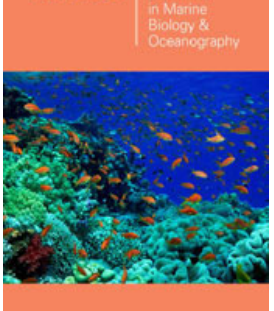

Examines in Marine Biology \& Oceanography

\section{Benefits of Publishing with us}

- High-level peer review and editorial services

- Freely accessible online immediately upon publication

- Authors retain the copyright to their work

- Licensing it under a Creative Commons license

- Visibility through different online platforms 